\title{
Design and Fabrication of an Automated Low-Cost Non-Contact Temperature Scanner and Sanitizer for Covid-19 Prevention
}

\author{
Olaitan Akinsanmi, *Abiodun E. Amoran, Ayodele S. Oluwole, P. C. Igwe and P. Adejuwon \\ Department of Electrical and Electronic Engineering, Federal University Oye-Ekiti, Nigeria \\ \{olaitan.akinsanmi l abiodun.amoran l ayodele.oluwole\}@fuoye.edu.ng
}

Received: 12-MAY-2021; Reviewed: 15-MAY-2021; Accepted: 22-MAY-2021

http://dx.doi.org/10.46792/fuoyejet.v6i2.638

\begin{abstract}
The rate at which the novel virus Covid-19 spread across the world in an alarming rate with high rate of death of the infected persons is quite disturbing, hence the need to checkmate its spread by quickly identifying persons with the symptoms of this viral infection. This paper discusses the development of an automated low-cost non-contact temperature scanner and sanitizer. The system automatically detects a human being, scans for temperature, and sanitizes the person with no interference required. The circuit for the system comprises an Arduino microcontroller, LCD display, relays, ultrasonic sensors, temperature sensor, $12 \mathrm{v}$ DC pump motion sensor and a high pressure $12 v$ DC pump. The temperature sensor (MLX90614) senses the temperature, certifies that the value is within the specified range as controlled by its ultrasonic sensor and displays the temperature on the LCD. Thereafter, an ultrasonic sensor activates the 12V DC pump to dispense the sanitizer. At the disinfectant chamber, the motion sensor will trigger the high-pressured DC pump when it senses movement, it dispenses the body sanitizer through the nozzles. $\mathrm{C}_{++}$was used to program the Arduino in Arduino user interface. The entire process takes 60 seconds and it helps to maintain personal preventive measures as well as detecting a possible symptomatic person as fever with high temperature which is one of the major symptoms of Covid-19. The device has been tested and works effectively, and it will be very useful for any organization with one or more buildings. It can be positioned at the entrance of buildings to sanitize and scan all staff and visitors against Covid-19.
\end{abstract}

Keywords- Arduino, Covid-19, Hand sanitizer, Ultrasonic sensor, Temperature Scanner

\section{INTRODUCTION}

C ovid-19 is a communicable respiratory disease caused by an extra strain of coronavirus that causes illness in human (ACDC, 2021). According to the World Health Organization (WHO) about 120 million cases of covid-19 have been reported globally and caused about 2.6 million deaths as March 2021 (WHO, 2021). In Nigeria, according to National Centre for Disease Control (NCDC) about 161,074 cases have been reported and about 2,018 deaths have also been reported while 146,072 and 12,984 are active and discharged cases respectively (NCDC, 2021). Considering the rapid spread of this virus and its effect, it is important to look into an effective system to curb the rate of spread and keeping it at bay.

COVID-19 pandemic has changed the world's economy outlook. For the first time in recent years many countries were under lockdown, making some businesses to shut down, decreasing the Gross Domestic Product of nations (Maliszewska, Mattoo \& van der Mensbrugghe, 2021). Medical experts on the other way round have been able to come out with the symptoms that can easily help in identifying persons infected with covid-19. Among other symptoms are high body temperature, cough and fever. Experts also came out with some preventive measures like regular hand washing, wearing of face mask and sanitizing surfaces among others measures that can reduce the rate of spreading of the coronavirus.

\footnotetext{
${ }^{*}$ Corresponding Author

Section B- ELECTRICAL/COMPUTER ENGINEERING \& COMPUTING SCIENCES Can be cited as:

Akinsanmi O., Amoran A. E., Oluwole A. S., Igwe P.C. and Adejuwon, P. (2021): Design and Fabrication of an Automated Low-Cost Non-Contact Temperature Scanner and Sanitizer for Covid-19 Prevention, FUOYE Journal of Engineering and Technology (FUOYEJET), 6(2), 30-34. http://dx.doi.org/10.46792/fuoyejet.v6i2.626
}

With the recent reopening of the Nigeria economy and resumption of business activities it becomes difficult to physically identify those with the symptoms of covid-19, fears are being envisaged about the safety of the general populace because of the large population of Nigeria, controlling of individuals to maintain social distancing is a very hard task. It will be very important to put measures that can easily help in identifying individual with the symptoms of covid-19 so as to prevent the spread.

The existing manual methods can only check the body temperature while dispensing hand sanitizer manually to individuals at the point of entry. However, this paper proposes an automatic chamber placed at the point of entry into organization's buildings to the body temperature with the help of a thermometer and sanitizing both hands and body in 60seconds.

\section{ReLated Work}

Edozie, Janat, and Kalyankolo (2020) designed and implemented a low-cost smart hand sanitizer dispenser with door controller using ATMEGA328P. An ultrasonic sensor was used to check for hands at the sanitizer outlet within the range of $10 \mathrm{~cm}$. The sanitizer was dispensed when distance between the hands and the outlet is less than $10 \mathrm{~cm}$ and once this condition is satisfied, the ultrasonic sensor then signals the microcontroller to activates the servo motor to dispense the sanitizer and after dispensing the sanitizer the electromagnetic lock was de-energized to unlock the door while the second servo motor opens the door otherwise the door remains closed while dispensing the sanitizer.

Similarly, Rusimamto et al. (2020) used Internet of things (IoT), infrared and ultrasonic sensor to automatically dispense sanitizer. The Infrared was used to sense heat and motion of objects within the range of 50millimeter and then send the signal to the Arduino to activate the 
pump. The ultrasonic sensor detects the distance between water and sensor in the range of 35centimeter and send signals to the Arduino to connect to the server. All these processes are controlled at the PC or smartphone to dispense the sanitizer. Although this process is contactless, but the range of infrared is too small and may render it less effective.

An IoT-based sensor-fusion assistive technology for COVID-19 disinfection was proposed by Sharnil, Anirban, and Ketan, (2020). This smart tunnel detects the height of humans at the height of 1.5 feets through an ultrasonic sensor and then sprays the sanitizer. The beauty of this work is the dual source of power, solar cell was used during the day, while solar power-bank was used at nights accompanied with a light-dependent sensing unit at nights. This smart tunnel disinfects in less than 10 s and can prevent an outsider from entering the chamber, besides this, there is an intelligent sensing unit that stores essential information on the cloud.

Rojo et al. (2020) developed a non-contact temperature reader with sanitizer dispenser. The microcontroller is the heart of the whole design, it controlled temperature reader which checks body temperature of human. The temperature also alerts the microcontroller when the temperature exceeds $38^{\circ} \mathrm{C}$ and the microcontroller controls the sanitizer dispenser to dispense promptly. Just like other designs, ultrasonic sensor is used to control the movement of the hands and submersible motor pump dispenses the sanitizer when all these processes have taken place.

Maurya et al. (2020) also proposed an Autonomous Advanced Disinfection Tunnel to Tackle External Surface Disinfection of COVID-19 Virus in Public Places. It comprised three disinfection processes. The first chamber sprayed a mist of herbal disinfectant solution or sodium hypochlorite solution, then the second chamber exposed humans to hot air at $70^{\circ} \mathrm{C}$ along with far-ultraviolent $\mathrm{C}$ rays with a wavelength between $207-220 \mathrm{~nm}$. The Arduino microcontroller controlled the two chambers automatically, the spraying of the sanitizer in chamber 1 is controlled by the electrostatic nozzle while multiple ultrasonic sensors was used to detect the entry and exit of persons within the range of $2-450 \mathrm{~cm}$ with red and green light showing entry and exit.

A chemical free disinfection process called the Ultraviolent germicidal irradiation (UVGI) method was proposed by Mahammedi, and Mahammedi, (2020) in their work titled "Standalone solar-powered ultraviolet mobile disinfectant: Bringing solar energy in the global fight against Covid-19. An UCV radiator produces an UVC light with a wavelength of about 200 to $280 \mathrm{~nm}$ capable of disinfecting air and other surfaces present deactivating fungi, bacteria, microbe and viruses including severe acute respiratory syndrome coronavirus (SARS-CoV) which causes Covid-19 by damaging their DNA and prevent replication. A standalone solar was an alternative source of energy to make the UCV available at all times.

SCTIMST (2019) developed an Ultrasonic Violent (UV) Based Facemask Disposal Bin containing disinfectant gateway and facemask disposal bin to protect waste collectors while performing their duties during covid-19 pandemic. It contained a chamber generating Hydrogen peroxide mist and UV based decontamination facility. The Hydrogen Peroxide fumes will decontaminate the body, hands, and clothes of a person while the UV system will decontaminate the chamber. This is made possible by the sensor mounted in the chamber which automatically detect entry and start the Hydrogen Peroxide mist generation process. The entire process is electronically controlled, and it is less time consuming.

\section{HaRdWARE DESIGN AND IMPLEMENTATION}

The section contains the implementation of the all the different components and the circuit diagram for the Covid-19 Based Automated Non-Contact Temperature Scanner and Sanitizer device as shown in figure 1. This contains the components described from sections 3.1 to 3.6

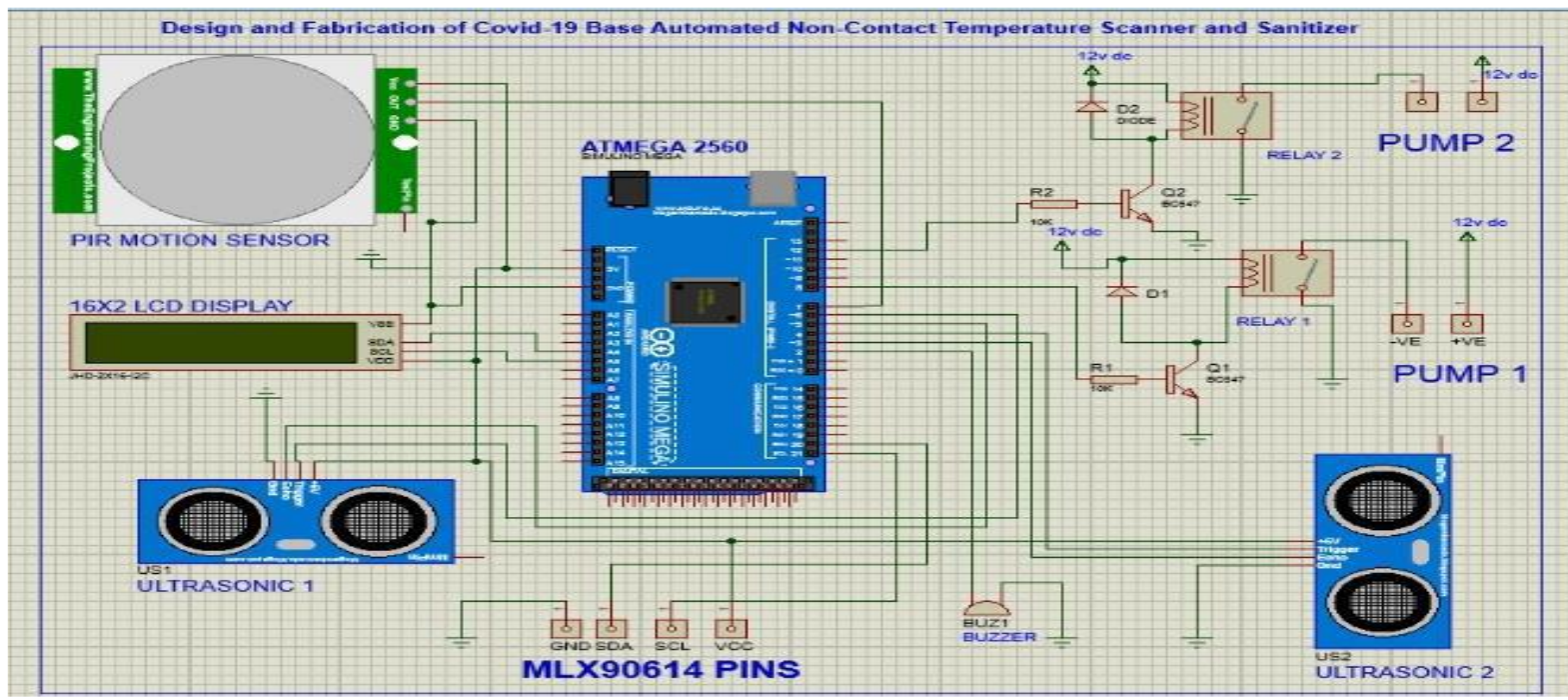

Fig. 1: Circuit diagram of the Covid-19 Based Automated Non-Contact Temperature Scanner and Sanitizer chamber 


\subsection{Power Section}

A $12 \mathrm{v}$ DC power supply is needed to power the whole system as such a $230 \mathrm{v}$ Alternating current source is step down to $12 \mathrm{v}$ using a step-down transformer. A 4 1n4007 diode D1-D4 were used for the process of rectification and to build a diode bridge rectifier that converts from Alternating Current (AC) to Direct Current (DC). An LM7812 voltage regulator was used to regulate the output voltage and to power the chamber. The pumps and Arduino board take its power from 12V DC while other components mlx90614 and other sensors operate at a voltage level of 5VDC and. The circuit diagram of the power section is shown in Figure 2.

\subsection{MLX90614 NON-CONTACT TEMPERATURE SENSOR}

The MLX90614 is an infrared thermometer for noncontact temperature measurement, integrated into the MLX90614 are a low noise amplifier, 17-bit ADC and powerful Digital Signal Processing unit thus achieving high accuracy and resolution of the thermometer. The Sensor has four pins namely the input voltage Vin, the Ground which is connected to the ground of the Arduino, the Serial data and Serial clock pins were connected to the Arduino which served as the communication link between the temperature sensor and the Arduino.

\subsection{ULTRASONIC SENSORS}

Two Ultrasonic sensors were deployed in the construction of this chamber, one was connected to both the $12 \mathrm{v}$ DC low pressured and $12 \mathrm{v}$ DC high pressured pump to dispense the hand sanitizer and to the disinfectant chamber that dispenses the body sanitizer through all the provided nozzles. The other ultrasonic sensor was connected to the motion sensor to check if an individual is within range to dispense the sanitizers.

\subsection{PUMPS}

The pump is a machine used to increase pressure and transfer liquid from one point to another. The advantage of the motorized Direct current pumps is that it be found in different voltage rating such $6,12,24$, or 32 volts of DC power and it can be submerged in water without negative effect. For this design, two 12v DC powered pumps were used in the construction, the first was a $12 \mathrm{v}$ DC high pressured and the $12 \mathrm{v}$ low pressured type.

\subsection{LIQUID CRYSTAL DISPLAY}

The Liquid crystal display, displayed readings taken by the temperature sensor. The two pins of the LCD were connected to the Arduino and the size of the LCD is 16 by 2. The I 2C LCD that is used in this project comes with a small add-on circuit mounted on the back of the module. This module features a PCF8574 chip (for I2C communication) and a potentiometer to adjust the LED back light.

\subsection{ReLAY MOdULES}

Relays are switches that open and close circuits either electronically or electro mechanically. Two relays were used in the construction, one $12 \mathrm{vDc}$ relay was used to control the high-pressure pump required by the Arduino board while the second $12 \mathrm{vDC}$ was used for switching the $12 \mathrm{v}$ low pressure pump.

In all, the I2C LCD display was connected to the i2c pins of the Arduino board (SCL and SDA pins) the LCD back light was adjusted for proper display. The mlx90614 temperature sensor was connected on the other i2c pins since Arduino mega board supports two i2c device in normal operation. The ultrasonic sensor was used to control the scanner and the DC pump to sense object closeness, to dispense the sanitizers. Then the $12 \mathrm{v}$ DC pump was also connected through the relay switch, its neutral pin is connected to the $12 \mathrm{v}$ source, power pin to the output pin of the relay and the relay input pin go to the Arduino pin. The Arduino used this connection to supply required power to make the relay drive the pump as when needed. The microcontroller controls the pump, when the designated ultrasonic sensor senses the required distance. Similarly, when the ultrasonic sensor that is made for the scanner senses the desired distance, the microcontroller reads the temperature sensor immediately and displays the value.

For the disinfectant chamber, a motion sensor is connected to one of the digital pins of the Arduino microcontroller as an input pin, this means that whenever the motion sensor senses a movement within the chamber, it signals the Arduino pin and the microcontroller. The $12 \mathrm{v}$ high-pressure pump was connected to the Arduino through a relay, the same way other pump was connected. The microcontroller gives an output to the relay anytime it receives an input from the motion sensor. The pump uses its electromechanical energy to drive the disinfectant liquid through the hose connection around the chamber and passes it in a mist form with the help of the mist nozzles.

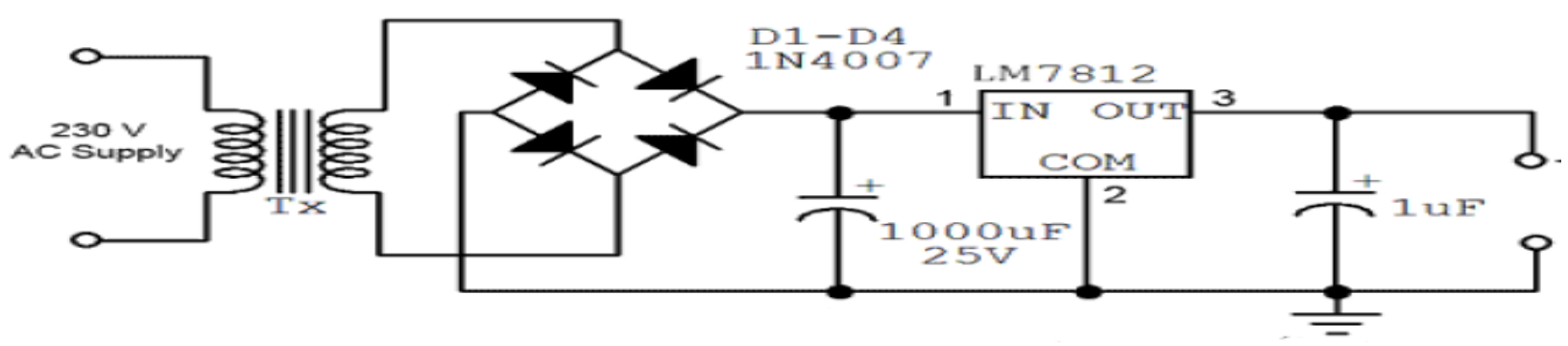

Fig. 2: The Power section circuit 


\subsection{SOFTWARE IMPLEMENTATION}

This section discusses the software and algorithm used in developing the Covid-19 Based Automated Non-Contact Temperature Scanner and Sanitizer as well as programming of the Arduino board Integrated Development Environment software, namely Arduino IDE and Proteus IDE. The operational flowchart of the software implementation is shown in Figure 4.

\subsubsection{Arduino Mega Microcontroller}

The microcontroller coordinates all other components connected to it and it controls the internal working as well as served as the interface for the entire system. The Arduino board contains sets of both digital (twenty-one) and analog (fifteen) input/output (I/o) pins that were interfaced to various expansion boards or breadboards (shields) and other circuits of the system. For this work, only the digital pins were used. It was programmed using $\mathrm{C}++$ programming language. The Arduino IDE is an open-source software that writes, compiles, and upload codes directly into the microcontroller. The version used in this design is version 1.8.9. The Arduino Integrated Development Environment is used for writing the desired software

code and for compiling, uploading code into the Arduino board. Its environment supports two programming language $\mathrm{C}$ and $\mathrm{C}++$. The sample diagram of the microcontroller is shown in Figure 3.

From the flowchart, the ultrasonic sensor 1 controls the temperature scanner if an individual in the chamber is within range the of the ultrasonic sensor, the temperature scanner takes the body temperature and displays it on the LCD if No that means the temperature is beyond the normal human body temperature and the buzzer alerts, if yes, the Ultrasonic sensor 2 checks whether the individual is with range so as to dispense the hand sanitizer. When the motion sensor is high, it senses an individual closeness in the disinfectant chamber then the DC pump dispenses the body sanitizer, if Low the process is repeated.

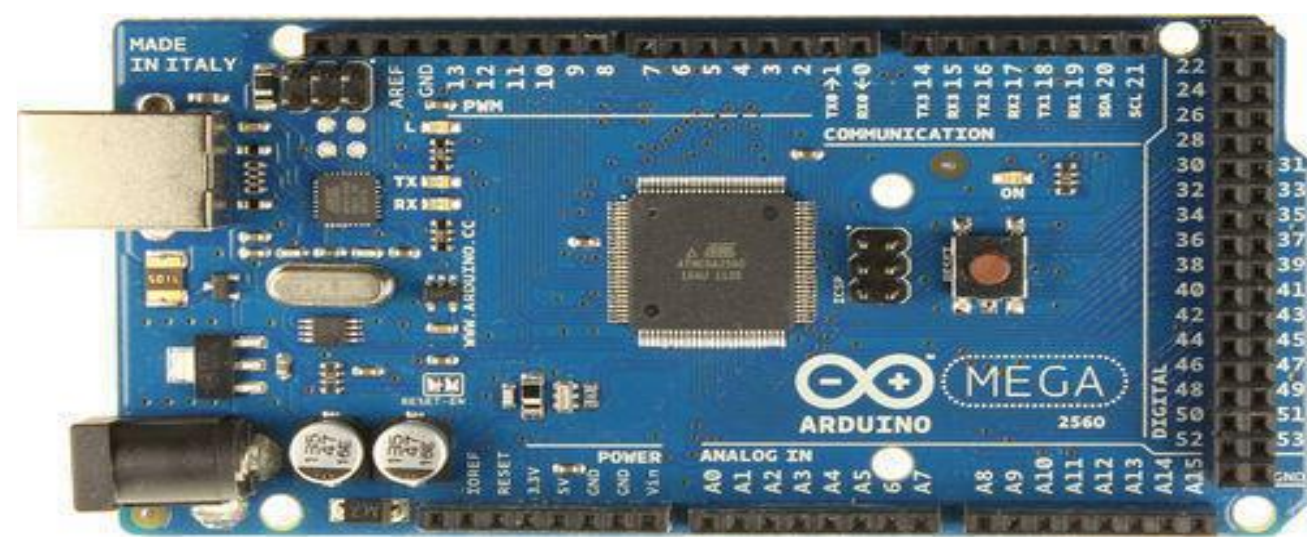

Fig. 3: An Arduino Microcontroller

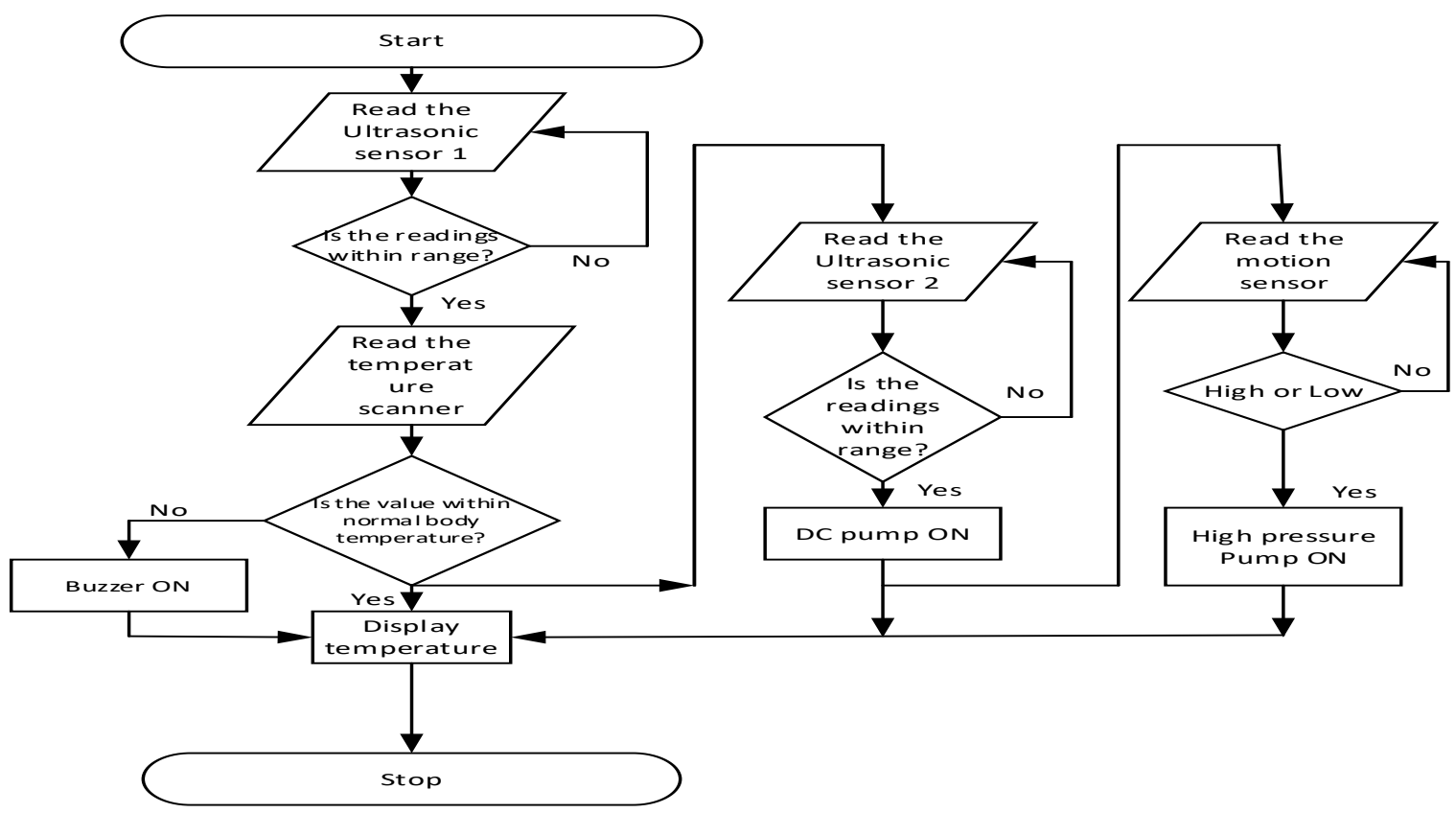

Fig. 4: Flowchart of the Automated Low-Cost Non-Contact Temperature Scanner and Sanitizer for Covid-19 Prevention 


\section{TESTING AND Evaluation}

The components were initially done on the Vero board to find out whether they are in good working condition before beginning the construction. The pumps were tested to ensure the $12 \mathrm{v}$ relays connected can drive them and they can pump disinfectant liquid to the appropriate point where they are needed and the written codes were run to make sure that they were error free. Table 1 show the comparison between the designed device temperature scanner and normal thermometer readings.

At the end of the construction, about five persons were made to go through this device for their respective temperature to be taken and both hand and body sanitizers dispensed. Initially, the temperature sensor had a little difficulty as it was later changed to a new one that is working okay.

\begin{tabular}{ccc}
\multicolumn{3}{c}{$\begin{array}{c}\text { Table 1. Comparison between the Designed device } \\
\text { Temperature scanner and normal thermometer }\end{array}$} \\
\hline S/N & $\begin{array}{c}\text { Designed Temperature } \\
\text { scanner }\end{array}$ & $\begin{array}{c}\text { Thermometer } \\
\text { Readings }\end{array}$ \\
\hline 1 & 36.6 & 35.9 \\
2 & 35.6 & 35.6 \\
3 & 34.59 & 34.7 \\
4 & 33.05 & 33.35 \\
5 & 36.05 & 36.6 \\
6 & 32.67 & 32.4 \\
7 & 36.14 & 35.1 \\
8 & 37.57 & 35.6 \\
9 & 35.35 & 33.1 \\
10 & 37.63 & 34.7 \\
\hline
\end{tabular}

The little discrepancies, especially serial number 8,9 and 10 , may be due to human error but ultimately the reads are very close each other

\section{Discussion}

This design is similar to what Edozie, Janat, and Kalyankolo, (2020), Rusimamto, et al. (2020), Sharnil, Anirban, and Ketan, K. (2020), Rojo, et al. (2020) did in that their methods could check body temperature and were also able to dispense hand sanitizer but the difference is the body sanitizer introduced by this research. The design by Sharnil, Anirban, and Ketan, (2020) take 10s, Edozie, Janat, and Kalyankolo, (2020) takes 30s while this design takes 60s because of its ability to check temperature, dispense hand and body sanitizer. Another similarity between almost all the reviewed literatures is that all were used in tackling covid-19 and the components used were almost the same.

\section{CONCLUSION AND FUtURE WORK}

A low cost Covid-19 Base Automated Non-Contact Temperature Scanner and Sanitizer has been designed and it is capable of checking body temperature and dispensing both hands and body sanitizer. For future works an alternative source of energy can be incorporated for the device to work 24hours daily.

\section{REFERENCES}

Africa CDC (2021). Coronavirus Diseases Update available at africacdc.org/covid19 accessed on March 18, 2021

NCDC (2021). National Centre for Diseases control. Covid-19 Case update available at covid19.ncdc.gov.ng accessed on March 18, 2021

Chan, K.H., Peiris, J.S.M., Lam, S.Y., Poon, L.L.M., Yuen, K.Y., Seto, W.H. (2011). The effects of temperature and relative humidity on the viability of the SARS coronavirus. Adv Virol. doi: 10.1155/2011/734690.

Edozie, E., Janat, W., Kalyankolo, Z. (2020). Design and Implementation of a Smart Hand Sanitizer Dispenser with Door Controller using ATMEGA328P. International Journal of Engineering and Information Systems (IJEAIS). 4(6), Pp14-18

Jithin, K., Subash, V.V. (2019) Scientists at Sree Chitra Tirunal Institute for Medical Sciences and Technology (SCTIMST), Trivandrum, Kerala, "Disinfection Gateway \& Facemask disposal bin to fight COVID-19"

Lee, J., Lee, J. Y., Cho, S. M., Yoon, K. C., Kim, Y. J., \& Kim, K. G. (2020). Design of Automatic Hand Sanitizer System Compatible with Various Containers. Healthcare informatics research, 26(3), 243-247. https://doi.org/10.4258/hir.2020.26.3.243

Mahammedi, N, A., Mahammedi, A. (2020). Standalone solarpowered ultraviolet mobile disinfects bringing solar energy in the global fight against COVID-19

Maurya et al (2020). Development of Autonomous Advanced Disinfection Tunnel to Tackle External Surface Disinfection of COVID-19 Virus in Public Places. Transactions of the Indian National Academy of Engineering 5:281-287 https://doi.org/10.1007/s41403-020-00141-7

Maliszewska, M., Mattoo, A., and van der Mensbrugghe, D. (2021). The Potential Impact of COVID on GDP and Trade: A Preliminary Assessment. World Bank Policy Research working paper 9211. Available online at open knowledge. Worldbank.org/handle/10986/33605.

World Health Organization. World Health Organization Covid-19 Dashbaord available at covid19.who.int accessed on March 18, 2021

SCTIMST. (2020) scientists develop disinfection gateway \& facemask disposal bin to fight COVID-19, Department of Science \& Technology. https:/dst.gov.in/sctimst-scientists-developdisinfection-gateway-facemask-disposal-bin-fight-covid-19. (Accessed 29 June 2020)

Sharnil,R., Anirban, S., Ketan, K. (2020). Smart epidemic tunnel: IoTbased sensor-fusion assistive technology for COVID-19 disinfection. https://doi.org/10.1108/IJPCC-07-2020-0091

Rojo, M. G., Sy, J. B., Calibara, E. R., Comendador, A. V., Degife, W., Sisay, A. (2020). Non-Contact Temperature Reader with Sanitizer Dispenser (NCTRSD). International Journal of Scientific and Research Publications, 10(9), pp 583 - 590

Rusimamto, P. W., Nurhayati, N., Yundra, E., Rahmadian, R., Widodo, A., Dermawan, M. A. (2020). Automatic Hand Sanitizer Container to Prevent the Spread of Corona Virus Disease. Advances in Engineering Research, International Joint Conference on Science and Engineering (IJCSE 2020). volume 196 